\title{
Ten Years of Activity at a Portuguese University Hospital Emergency Department: A Retrospective Observational Study
}

Humberto S Machado ${ }^{1,2^{*}}$, Catarina Nunes ${ }^{1,3}$, António Marques ${ }^{1,2}$, Isabel Almeida ${ }^{1,2}$, António José Barros ${ }^{1}$, Eurico Castro Alves ${ }^{1,2}$, António Sousa Pereira ${ }^{2}$, José Barros ${ }^{1,2}$ and Paulo Barbosa ${ }^{1,2}$

${ }^{1}$ CHP-Centro Hospitalar do Porto, Porto, Portugal

${ }^{2}$ ICBAS-Instituto Ciências Biomédicas Abel Salazar, Universidade do Porto, Porto, Portugal

${ }^{3}$ UA-Universidade Aberta, Departamento de Ciências e Tecnologia, Delegação do Porto, Portugal

\begin{abstract}
Background: Emergency department (ED) management relies on real-time information. Patient flow, lengthof-stay (LOS), complaint related readmissions, and patients that leave without being seen (LWBS), are monitoring parameters. The objective of this study was to evaluate activity time trends regarding ED at Centro Hospitalar do Porto from 2007 to 2016.

Methods: Analysis of ED data warehouse (Alert ${ }^{\circledR}$ Emergency Room) was carried out. Manchester Triage System (MTS) is used, and the mentioned priorities (P1, P2, P3, P4 and P5) correspond to its terminology. Spearman correlation between variables was applied.

Results: Patient records from 1.256.900 ED visits were evaluated. ED demand increased $16 \%$. Priority 2 increased by $50 \%(p<0.001)$. A decrease of priority $4(p<0.001)$ was observed. Patients that visit ED for unrelated reasons (labeled white) decreased $(p<0.001)$. Difference between patients' medians at different day hours $(p<0.001)$ was found. A steady peak influx between $10 \mathrm{~h}-11 \mathrm{~h}$ and $14 \mathrm{~h}-16 \mathrm{~h}$ was found and significant increase was observed during night/dawn hours (3-8 h). No differences were observed between weekdays affluence. A priority difference was observed in weekdays, with a Monday peak for P3 and P4 priorities $(p<0.001)$. A decrease in all patients' ages was observed till sixty years old $(p<0.001)$; A raise was noticed after eighty years old $(p<0.001)$. Nevertheless, the LWBS was kept under $2.5 \%$ LOS under $5 \mathrm{~h} 30 \mathrm{~m}$, with a sustained time-to-first-medical-observation (TFMO) under 70 minutes. Complaint indexed to readmissions (CIR) remained constant.
\end{abstract}

Discussion: A constant LOS, TFMO, CIR, and small LWBS indicate a positive trend of ED clinical management. Population's characteristics should be taken in to consideration to maintain these results.

Conclusions: ED affluence increased during the studied period, especially by the older and the sicker Primary care increased availability did not influence ED demand. Real time data storage helped to maintain clinical management by evidence based decisions.

Keywords: Emergency department management; Crowding; Lengthof-stay; Emergency department readmissions

\section{Introduction}

Emergency Department (ED) crowding causes dysfunction and longer waiting times for first medical observation, with delays in admission, and higher risk of infectious disease transmission (as noticed in an outbreak of severe acute respiratory disease in Canada) [1].

Presentation at ED during high occupancy periods is associated with an increased in-hospital mortality at 10 days [2]. Occupancy is a measure of ED crowding based on the number of patients receiving treatment [3].

Delays in transfer from ED to a inpatient bed are also associated with increased hospital length of stay (LOS) [4,5].

All of these phenomena associated with the problem of overcrowding has grown with astonishing ubiquity across the world with growing concern in the United States of America (USA) [6,7], United Kingdom (UK) [8], Australia [9] amongst other countries.

Being part of a reasonably complex equation that might explain ED crowding, the imbalance between allocated personnel, the ED physical space and the amount of patients (waiting to be seen, undergoing assessment and treatment or waiting for departure), must be addressed in order to overcome this problem [9].

Despite all these mentioned causes, the main reason for ED overcrowding is frequently external in nature, namely the ED capacity for patient influx of a population with increased severity of illness [6]. Furthermore, there is evidence that input, throughput and output indicators may be altogether linked to ED crowding [10]. Input indicators of ED crowing include 5\% of left-without-being seen (LWBS) patients, and a greater than 5 minute average waiting time for triage [10]. Throughput indicators that are linked to ED crowding include: Occupancy rate over 100\% (number of patients over the official designated capacity), when the total ED average LOS surpasses 4 hours, or when an urgent patient waits more than 30 minutes for the first medical observation [10]. Output measures aligned with ED crowding encompass: when less than $90 \%$ have left the ED 2 hours after the decision to admit to the ward, or when more than $10 \%$ admitted for patients still wait for a bed [10].

*Corresponding author: Humberto S Machado, CHP-Centro Hospitalar do Porto Portugal, Tel: +351-935848475; E-mail: hjs.achado@gmail.com

Received January 22, 2018; Accepted February 20, 2018; Published February 27,2018

Citation: Machado HS, Nunes C, Marques A, Almeida I, Barros AJ et al. (2018) Ten Years of Activity at a Portuguese University Hospital Emergency Department A Retrospective Observational Study. Gen Med (Los Angel) 4: 309. doi 10.4172/2327-5146.1000309

Copyright: (c) 2018 Machado HS, et al. This is an open-access article distributed under the terms of the Creative Commons Attribution License, which permits unrestricted use, distribution, and reproduction in any medium, provided the original author and source are credited. 
Some initiatives have been proposed and implemented to improve ED throughput, namely a senior doctor led system in the ED front office; however, despite some time improvements in the less serious conditions, overall ED turnaround time did not change significantly [11], signifying that a more systemic change is needed across the overall hospital.

The availability of alternatives to $\mathrm{ED}$ use and demand have been promoted in several countries, either by telephone triage and counseling or by the use of walk-in centers; none of these alternatives have significantly impacted ED attendance [11], and some might had the contrary effects, actually increasing ED demand [11].

The Centro Hospitalar do Porto (CHP) emergency department had implemented the Manchester triage system in the year 2000. Thus, much of the information found is based on the five-triage levels that this system incorporates.

In Portugal, doctors from the several medical specialties with a direct intervention in emergent and urgent cases compose most of the ED medical staff, mainly because there is no emergency medicine specialty that might suffice this need, as happens in several countries, like the UK, Canada, USA, and others.

The objective of this study was to assess the magnitude of crowding in the ED of a Portuguese university hospital over a 10 -year period, in order to identify and implement health quality improvement measures.

\section{Methods}

CHP is a tertiary university hospital with eight hundred and fifty inpatient beds, composed of a maternity/child unit, a day-case/ ambulatory surgery unit and a main hospital building in which there is an ED that covers a direct population of approximately 360.000 people, and serves as a reference center for about 1.700.000, with full coverage of all relevant ED specialties. Pediatrics, gynecology and obstetrics, have a separate acute clinic emergency setting in CHP, not included in this study. Cardiothoracic and plastic surgery emergency services are centered in other metropolitan hospitals.

During 2000 CHP implemented the MTS. This is a five level triage system with the following significance. Priority 1 (P1 red color), emergent-target time for medical observation 0 minutes; Priority 2 (P2 orange color), very urgent-target time for medical observation 10 minutes; Priority 3 (P3 yellow color), urgent-target time for medical observation 60 minutes; Priority 4 (P4 green color), less urgent- target time for medical observation 120 minutes; Priority 5 (P5 blue color), not urgent-target time for medical observation 240 minutes. Nevertheless, two other categories are presented, namely the no triage patients and the patients identified with a sixth color-white (specially authorized by the Manchester Triage Group for the Portuguese hospitals). These two categories identify per si potential dysfunction on this and other EDs in Portugal. The no triage patients represent those patients that come to the hospital for a daycare appointment and have a sudden acute episode of his or her illness, being by this reason redirected to the ED for stabilization of the acute episode. The "sixth color patients" (white), mean that there are some patients that come to the ED with absolute no identifiable clinical reason (i.e. to ask for a prescription, to control an old acute condition formerly treated in the ED, but without a clinical presentation of acute symptom or sign). Thus, the White color means no priority for ED-without target time, to be discharge as soon as possible, and the No triage patient, is a patient that came from hospital daycare or else where inside the hospital, to the ED for stabilization.

The CHP ED database was instituted during 2004 as part of a complete paper-free electronic medical record implementation that allowed gathering of clinical, socio-economic and logistic data of observed patients.

This database was built with data warehouse methodology, allowing consultation of predefined and customized data variables and query formulation. The ED database was accessed and information from the last ten years of activity was collected. Main standard queries were studied from 2007 to 2016, covering the most relevant areas to illustrate ED daily activity.

Monthly and annually based information was collected, regarding main patient complaints at department triage, triage levels, time to first medical observation, ED length of stay, proportion of left-withoutbeing-seen (LWBS) patients, clinical indexed readmissions, amongst several others that might clarify ED overall activity; in addition, emergency department records regarding human resources allocation were consulted in order to better understand and/or plan future quality improvement interventions.

Statistical analysis used the Spearman correlation, and the KruskalWallis non-parametric one-way ANOVA. Results are expressed as number or percentages, and statistical significance was establish for $\mathrm{p}<0.05$. Analyses were done using IBM SPSS 22 .

\section{Results}

All data extracted in this study were totally anonymised. All ethical issues were thorough reviewed and authorized by the administration board as an audit to the ED.

During the study period (2007-2016) a total of 1256900 patients came to the ED. These patients' data were studied regarding several topics pertinent to ED activity. During this period a standard healthcare provider team was allocated to the department with a consistent human resource composition, Table 1.

Table 2 shows the number of patients that came to the ED during the last 10 years, according to the Manchester triage system (MTS).

The total number of patients that have been observed has been relatively constant during the studied period. However, a significant increase in P2 patients is observed (Spearman Rho $\mathrm{R}=0,976 \mathrm{p}<0.001$ ) during these ten years, with decrease in $\mathrm{P} 4$ patients (Spearman Rho $\mathrm{R}=0.952 \mathrm{p}<0.001)$ and also in patients labeled with the white color (Spearman Rho R=0.818 p $<0.001$ ).

Besides the overall ED workload showed on Table 2, the hourly patient influx had a consistent pattern over the study period (Figure 1A); nevertheless, a significant increase of patients between 2 and 8 oclock in the morning $(\mathrm{p}<0.05)$ and a decrease between $14 \mathrm{~h}-22 \mathrm{~h}(\mathrm{p}<0.05)$ were observed. Figure 1B shows a significant difference between median numbers of patients arriving at different hours to the ED.

ED global affluence did not show a significant difference between weekdays; however a significant difference between priorities was

\begin{tabular}{|c|c|c|c|}
\hline & $\mathbf{0 8 h 0 0 - 1 4 h 0 0 ~}$ & $\mathbf{1 4 h 0 0 - 2 0 h 0 0}$ & $\mathbf{2 0 h 0 0 - 0 8 h 0 0 ~}$ \\
\hline Medical doctors (all specialties) & 38 & 38 & $\mathbf{2 8}$ \\
\hline Nurses & 14 & 14 & 14 \\
\hline Operations assistants & 12 & 12 & 12 \\
\hline Administrative assistants/clerks & 6 & 4 & 4 \\
\hline Transport assistants & 5 & 5 & 4 \\
\hline Security personnel & 4 & 4 & 4 \\
\hline
\end{tabular}

Table 1: Emergency department healthcare provider team 


\begin{tabular}{|c|c|c|c|c|c|c|c|c|c|c|}
\hline & \multicolumn{9}{|c|}{ Year } \\
\cline { 2 - 10 } & $\mathbf{2 0 0 7}$ & $\mathbf{2 0 0 8}$ & $\mathbf{2 0 0 9}$ & $\mathbf{2 0 1 0}$ & $\mathbf{2 0 1 1}$ & $\mathbf{2 0 1 2}$ & $\mathbf{2 0 1 3}$ & $\mathbf{2 0 1 4}$ & $\mathbf{2 0 1 5}$ & $\mathbf{2 0 1 6}$ \\
\hline P1 - Red & 999 & 893 & 931 & 1008 & 930 & 949 & 947 & 951 & 892 & 885 \\
\hline P2 - Orange & 10622 & 10367 & 10916 & 11919 & 12012 & 12008 & 12354 & 14150 & 14980 & 16494 \\
\hline P3 - Yellow & 80719 & 78821 & 81647 & 84503 & 80908 & 77489 & 80285 & 85090 & 84063 & 86876 \\
\hline P4 - Green & 31517 & 29782 & 28483 & 24539 & 26918 & 22728 & 21255 & 18834 & 17108 & 19334 \\
\hline P5 - Blue & 837 & 851 & 760 & 499 & 740 & 674 & 747 & 875 & 984 & 1462 \\
\hline White & 2791 & 4888 & 6717 & 6950 & 4681 & 2685 & 2269 & 1617 & 1542 & 1597 \\
\hline No triage & 1163 & 1163 & 1747 & 2159 & 1979 & 1729 & 1749 & 1708 & 1634 & 1597 \\
\hline Patients/year & 128648 & 126765 & 131201 & 131577 & 128168 & 118262 & 119606 & 123225 & 121203 & 128245 \\
\hline Daily average & 352 & 347 & 359 & 360 & 351 & 324 & 327 & 337 & 332 & 351 \\
\hline
\end{tabular}

Table 2: Number of patients that came to ED per year (2007-2016).

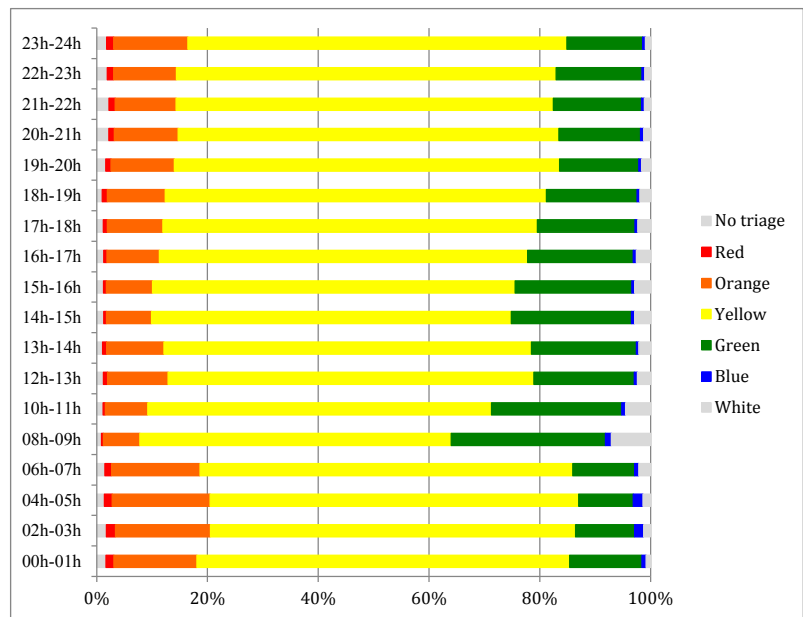

Figure 1A: Hourly patient influx to CHP emergency department (2007-2016) according to manchester triage system.

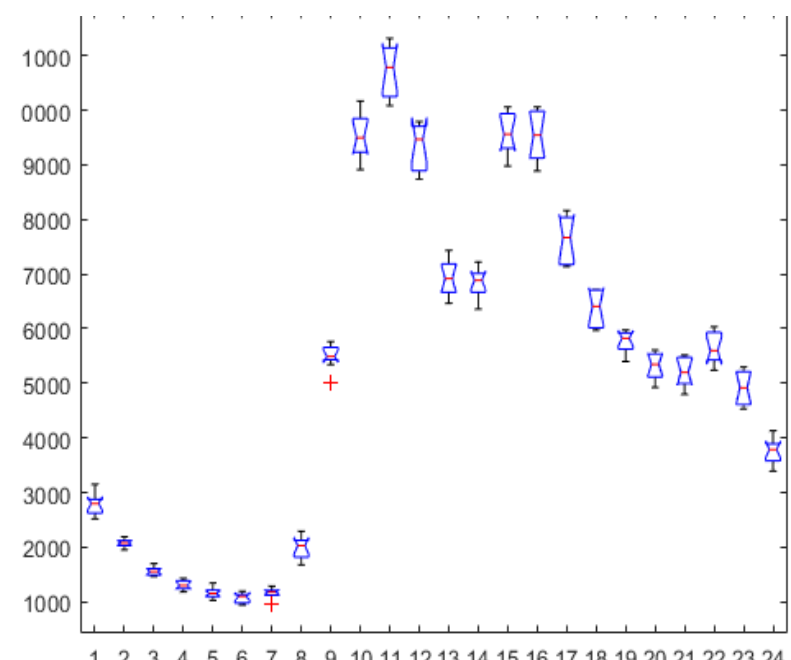

Figure 1B: Distribution of influx of patients at the ED per hour of the day. difference between median numbers of patients arriving at different hours to the ED (Kruskal-Wallis test - Non-parametric One-Way ANOVA $p<0.001$ ).

observed ( $\mathrm{p}<0.001)$; a priority 3 (yellow) and 4 (green) peak was observed on Mondays, a decrease in priority 3 was noticed on Saturdays and Sundays, and of no less importance two non-significant peaks were noticed, one of priority 4 (green) was on Sundays and one of priority 2 (orange) on Mondays (Figure 2).

Figure 3 shows the yearly affluence by patient age; a significant decrease of patient till the age of sixty was observed $(\mathrm{p}<0.001)$. An increase in patients older than 90 was noticed, with a stable affluence number of patients between eighty and ninety years old.

The ED medical team includes several specialties, being some of them quite busy (over 25.000 patients per year), and others with lower number of patients (under 5.000 patients per year); Figure 4 shows the ED workload of the busiest specialties. A significant increase $(p<0.001)$ was workload was observed for General Medicine. Neurosurgery, Ophthalmology, Nephrology, Endocrinology had significant decreases in workload $(\mathrm{p}<0.001)$. The yearly evolution of the most frequent ED patient presenting clinical complaints is shown in Figure 5.

The most frequent clinical complains that motivated patients to attend the ED are shown in Table 3. The monthly evolution of the most frequent complaints that impel patients to the ED is shown in Figure 6.

Regarding the most frequent complaint that brings patients to the ED, namely limb problems, a clear contrast was found between winter (November and December) and summer months (may to September), with the most significant July $(\mathrm{p}<0.001)$ (Figure $6 \mathrm{~A})$. Also a significant difference between January and June $(\mathrm{p}<0.05)$ was found regarding the complaint "unwell adult" (Figure 6B). The third most frequent complaint, "ophthalmological problems" exhibited significant differences among months but without a special month that stood out from the others (Figure 6C). A clear contrast was again found regarding the complaint "abdominal pain", with a significant increase during summer $(\mathrm{p}<0.001)$ (Figure 6D). Dyspnea as the complain that brought patients to the ED a high significant value was encountered $(\mathrm{p}<0.001)$ between December and July; nevertheless other winter months had also significant values when compared to summer months (Figure $6 \mathrm{E})$. Lumbar pain was more frequent during summer $(\mathrm{p}<0.001)$ with peak significance in July and August (Figure 6F). On contrary, Thoracic pain occurred more significantly during winter with peak on January $(p<0.001)$ (Figure 6G). A significant contrast was seen between winter and summer months regarding ear problems (Figure $6 \mathrm{H}$ ), with a peak incidence on July and August $(\mathrm{p}<0.001)$. Wounds and urinary problems also peaked during summer, with $\mathrm{p}<0.05$ and $\mathrm{p}<0.001$ respectively.

Main discharge diagnosis found during the study period is presented on Figure 7. A significant increase was found in respiratory diseases $(\mathrm{p}=0.002)$, cardiac and circulatory conditions $(\mathrm{p}=0.043)$, skin and contagious diseases $(\mathrm{p}<0.001)$ and also undefined morbid states $(\mathrm{p}<0.001)$ 


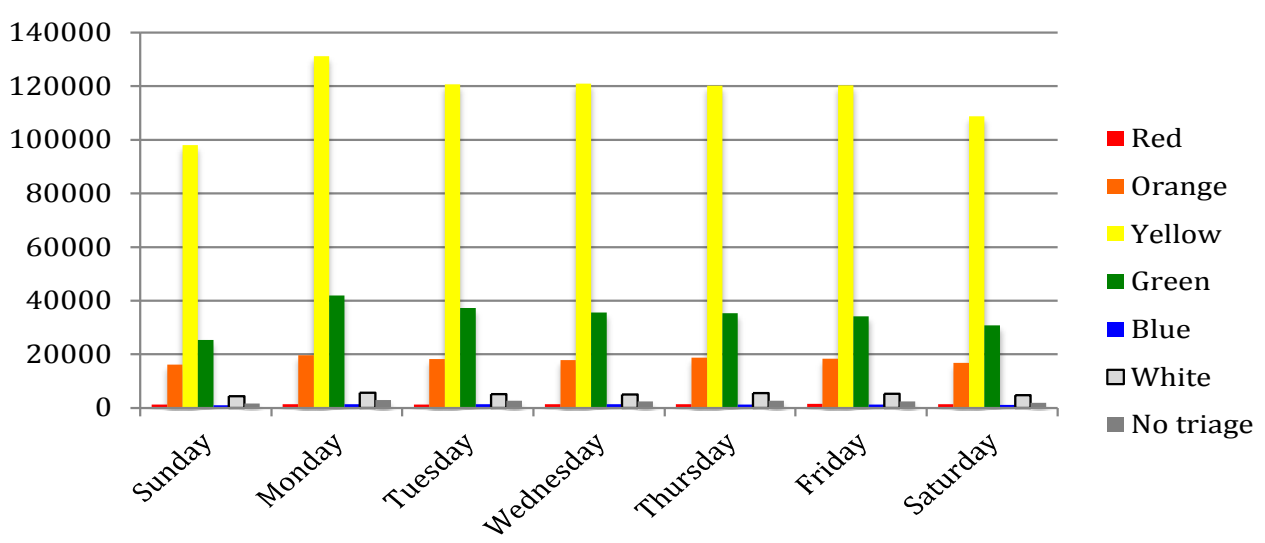

Figure 2: Number of patients by priority and day of the week.

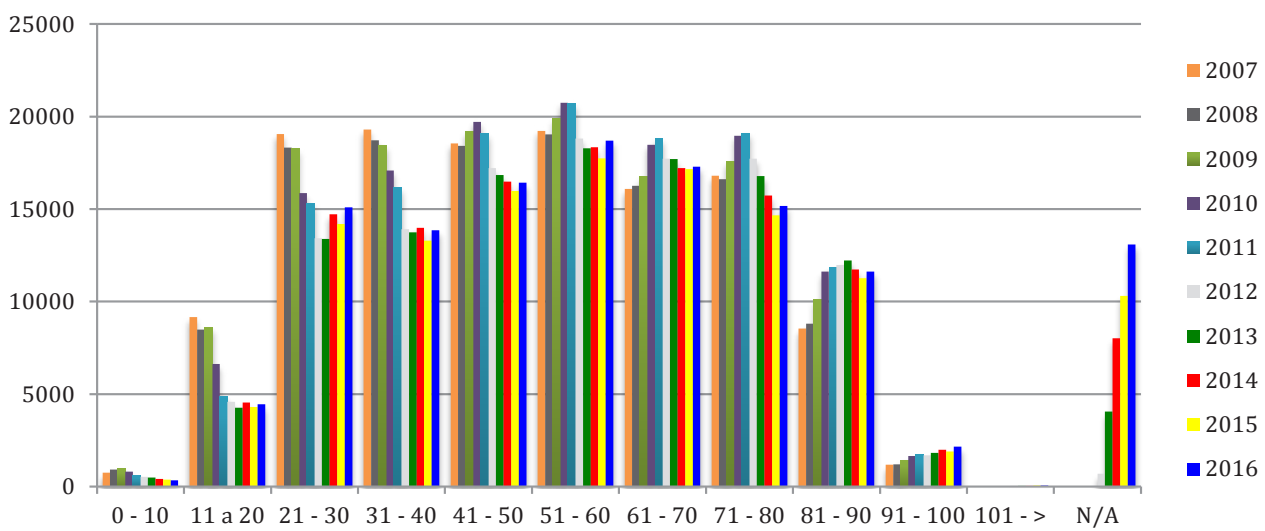

Figure 3: Year patient affluence by age.

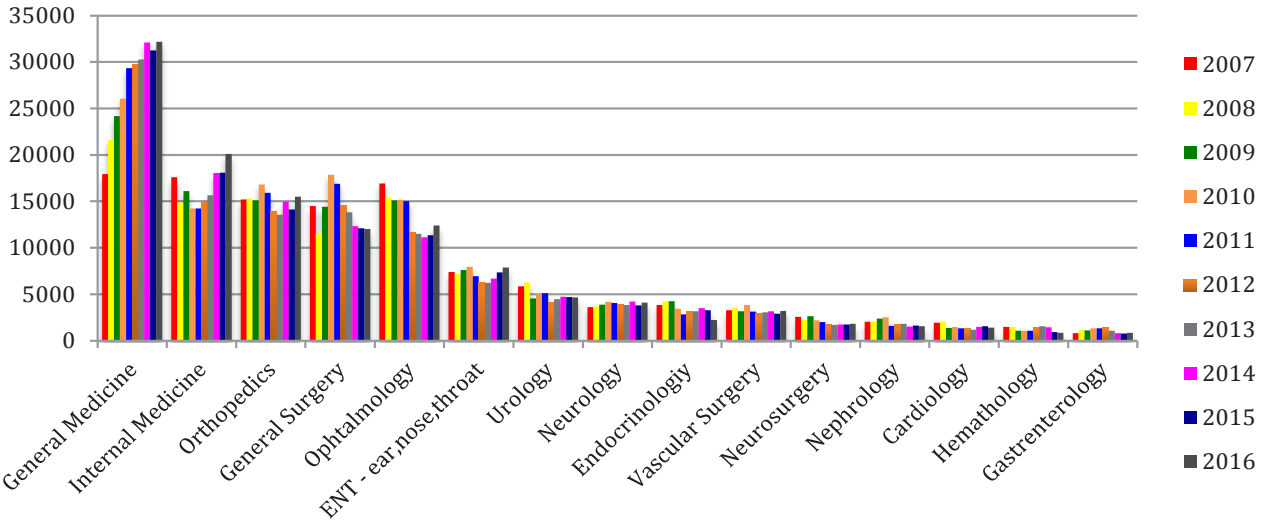

Figure 4: Year evolution of specialty work load in ED.

After ED observation, stabilization and treatment, several destinations are usually allocated to each patient. Figure 8 shows the destinations' evolution during the study period. A significant decrease of patients discharged home is observed $(\mathrm{p}<0.001)$ along with a significant increase of ward admission $(\mathrm{p}=0.015)$, furthermore, a decrease of outpatient clinic routing was noticed $(\mathrm{p}=0.008)$.

During the study period a total of 108.559 patients were admitted to an inpatient ward, which represents $8.64 \%$ of total ED patients.
Figure 9 presents the yearly evolution of ward occupancy of in the ED intermediate care unit with its significant increase $(p=0.02)$. Orthopedics $(\mathrm{p}=0.004)$, internal medicine $(\mathrm{p}<0.001)$, Cardiology $(\mathrm{p}=0.012)$, Neurosurgey $(\mathrm{p}=0.011)$, Urology $(\mathrm{p}=0.009)$, intensive care $(\mathrm{p}=0.032)$ (Figures 10 and 11).

Figure 12 shows the evolution of imaging requests over the study period. A significant increase in ultrasound studies was observed $(\mathrm{p}=0.001)$, along with $\mathrm{X}$-ray studies $(\mathrm{p}<0.001)$ and Magnetic Resonance Imaging $(\mathrm{p}=0.001)$. 


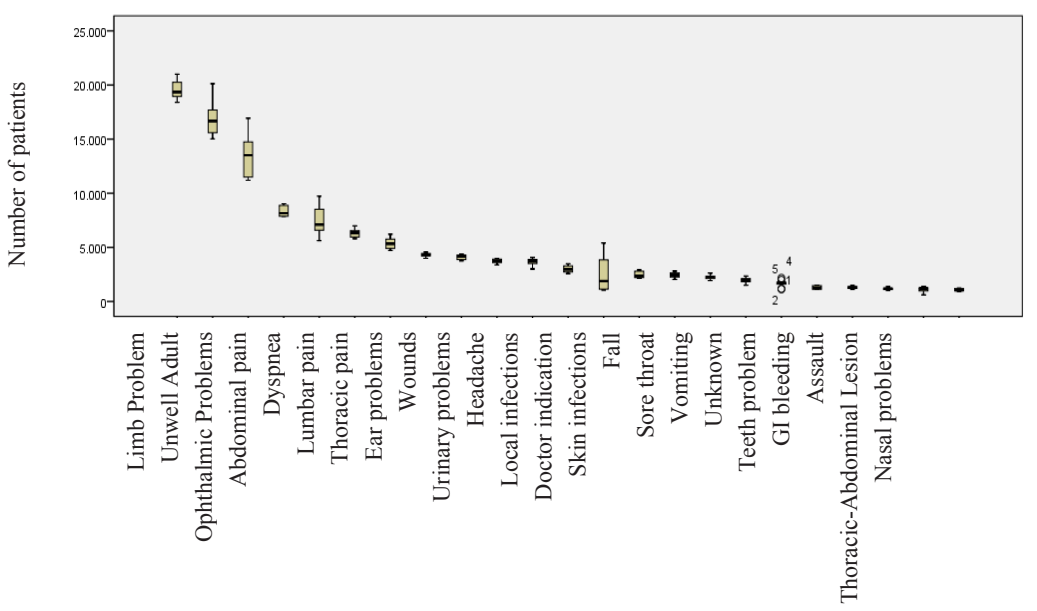

Figure 5: Distribution of ED admition complains.

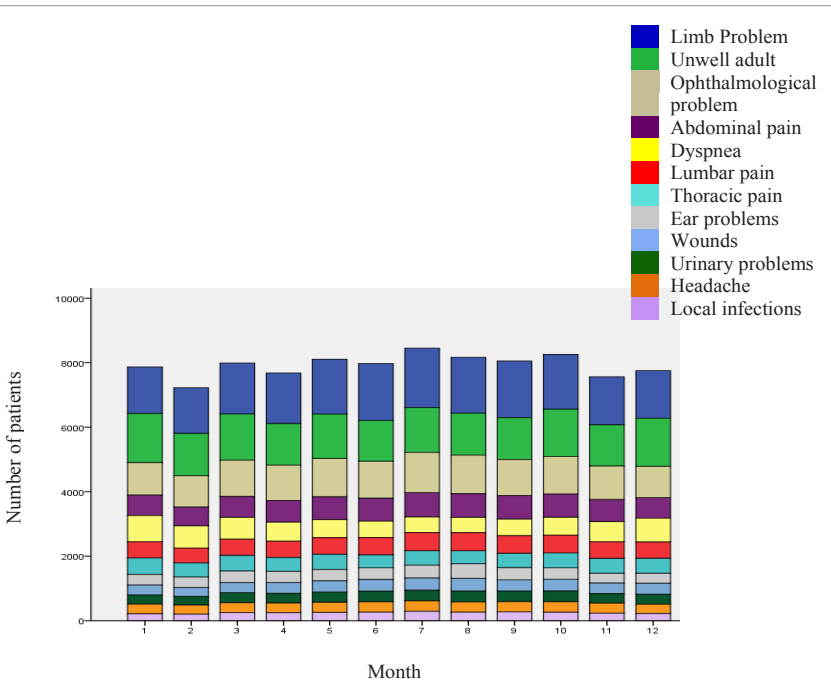

Figure 6: Monthly evolution of ED clinical complains.

The matter of ED episode financing has gained increasingly relevant importance. Figure 13 shows how this issue has evolved over the last ten years in this ED. The patient that comes to the ED and doesn't have an identified payer of this medical service increased significantly $(\mathrm{p}<0.001)$. All other types of payers decreased significantly during the study period $(\mathrm{p}<0.001)$.

One of the most valued parameters of ED performance is the time to initial medical observation. Figure 14 shows this indicator's evolution during the study period priority adjusted. A significant difference between priority waiting time medians was observed $(\mathrm{p}<0.0001)$. Priority 1 (red) and priority 2 (orange) did not differ in time between them, for first medical observation. However, all other priority waiting times had significant differences. During the study period waiting time for priority 1 (red) $(\mathrm{p}=0.038)$ and priority 2 (orange) $(\mathrm{p}=0.002)$ both decreased.

The overall time to first medical observation did not vary over the yearly studied period. Figure 15 shows its monthly evolution, with empirical increase in December and January.

The ED length of stay (LOS), as indicated by duration of ED episode,

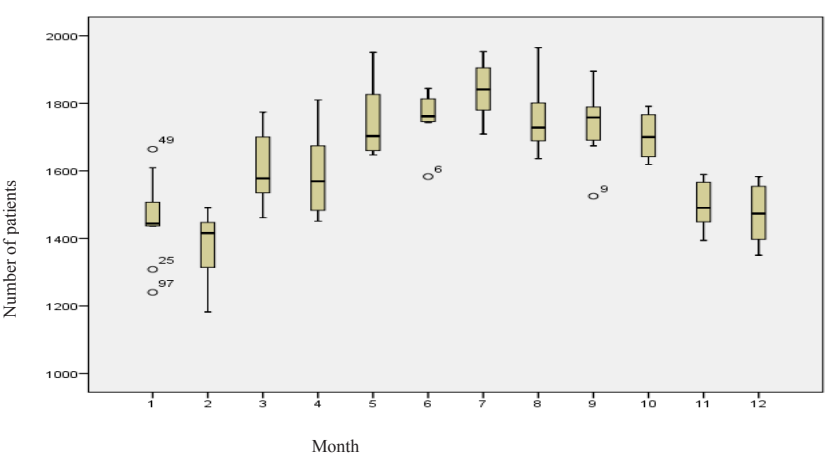

Figure 6A: Monthly evolution of patients with limb problems coming to ED.

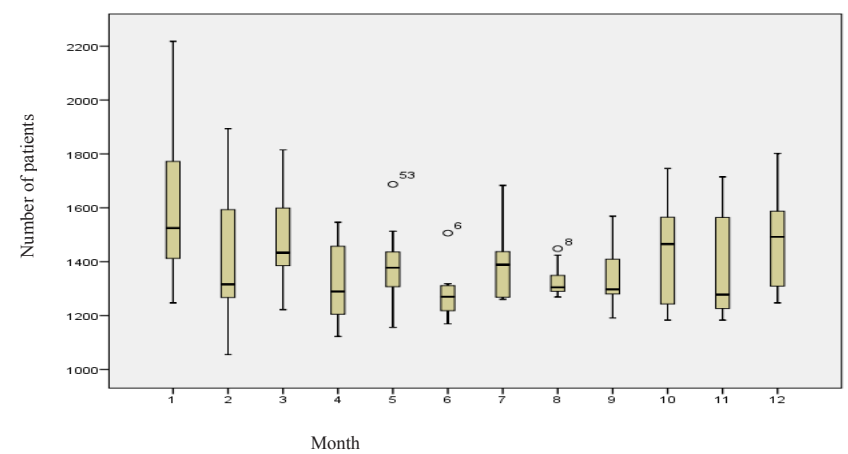

Figure 6B: Monthly evolution of patients with the complaint unwell coming to ED.

is highly valorized either by patients or by the political establishment. Figure 16 shows the ED LOS over the study period, by the monthly evolution. A significant difference between time medians of LOS was observed between months $(\mathrm{p}<0.0001)$, furthermore a significant difference between years LOS was also observed $(\mathrm{p}=0.0003$ ). During the yearly study period a significant increase in ED LOS was observed in several months, namely February $(\mathrm{p}=0.029)$, March $(\mathrm{p}=0.048)$, August $(\mathrm{p}=0.019)$ and October $(\mathrm{p}=0.033)$

Returning to the ED with the same complaint in the next 72 


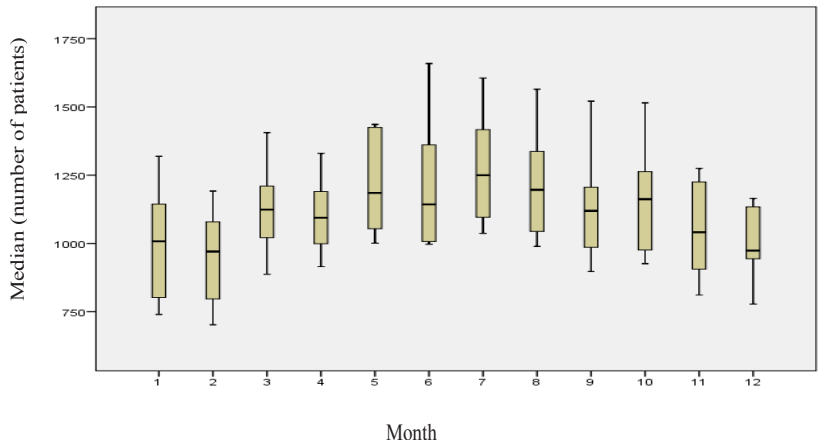

Figure 6C: Monthly evolution of patients with ophthalmological problems coming to ED.

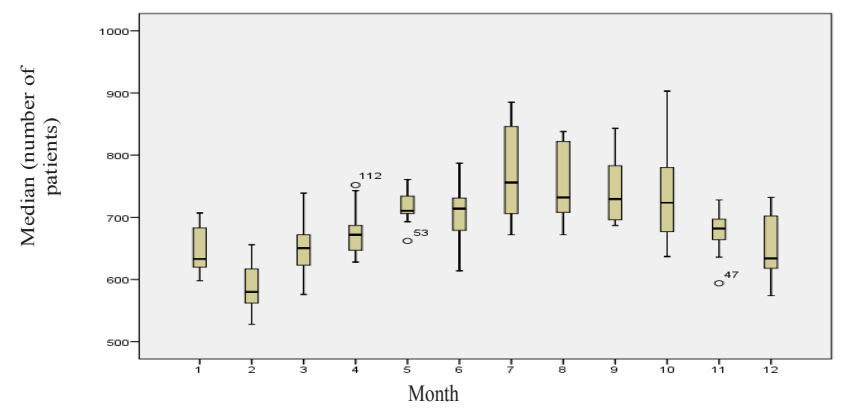

Figure 6D: Monthly evolution of patients with abdominal pain coming to ED.

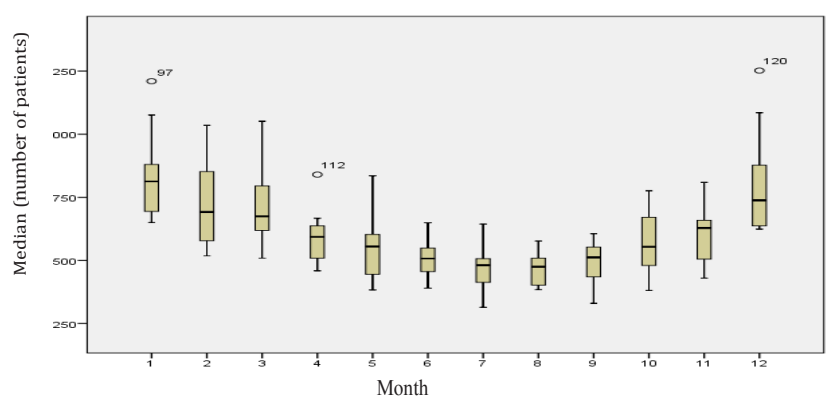

Figure 6E: Monthly evolution of patients with dyspnea coming to ED

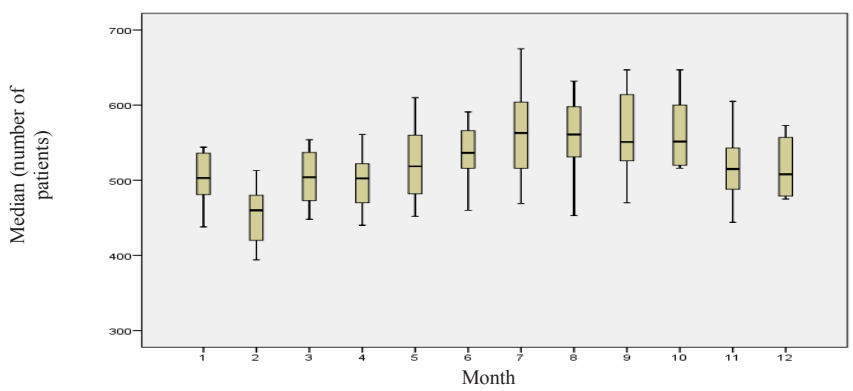

Figure 6F: Monthly evolution of patients with lumbar pain coming to ED.

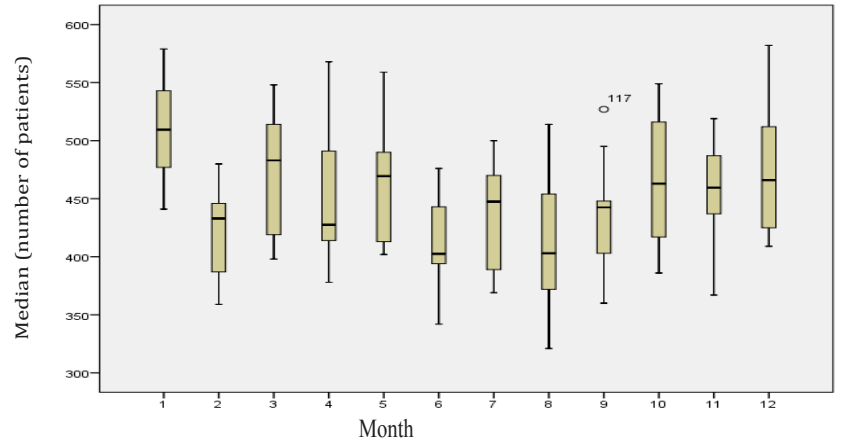

Figure 6G: Monthly evolution of patients with thoracic pain coming to ED.

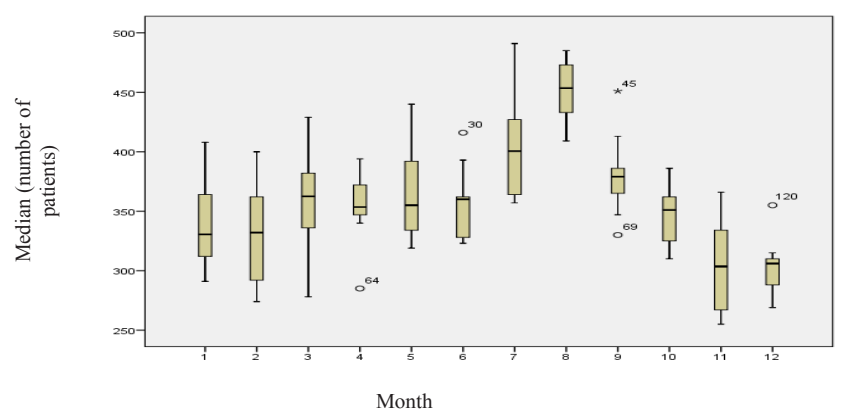

Figure $6 \mathrm{H}$ : Monthly evolution of patients with ear problems coming to ED

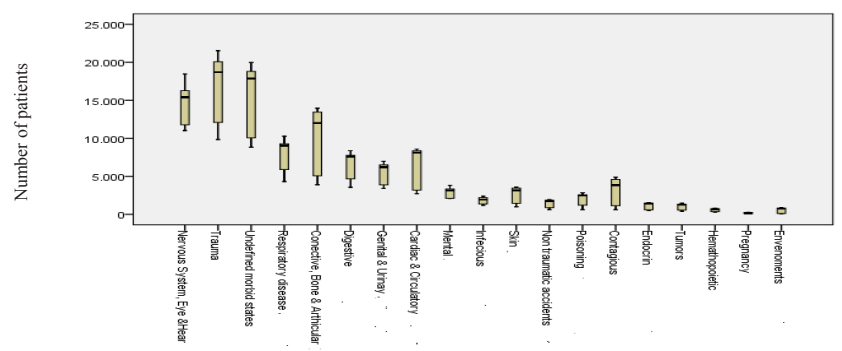

Figure 7: Distribution of the main discharge diagnosis per year (number of patients).

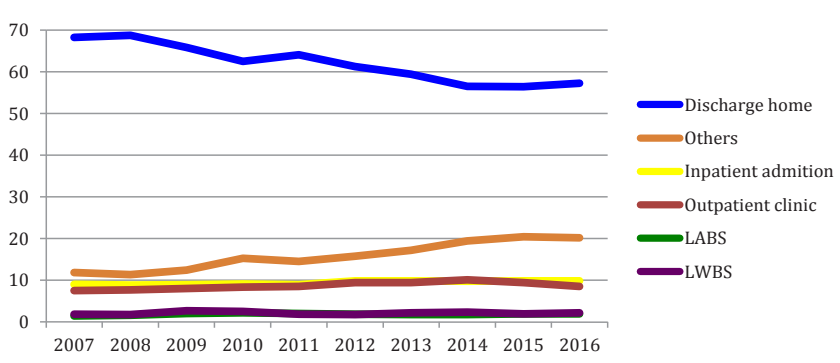

Figure 8: Patients destinations after ED visit (LWBS - left without being seen LABS - left after being seen).

hours shows how the department performs but may also demonstrate opportunities for better clinical management throughout the hospital. Figure 17 shows the 72 hours cumulative readmissions rate indexed to the presenting complaint. Readmissions due to dyspnea significantly 


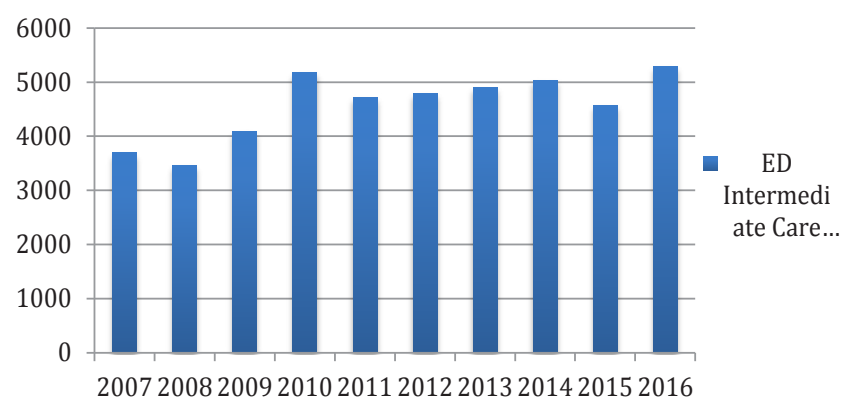

Figure 9: Admition to the ED intermediate care unit.

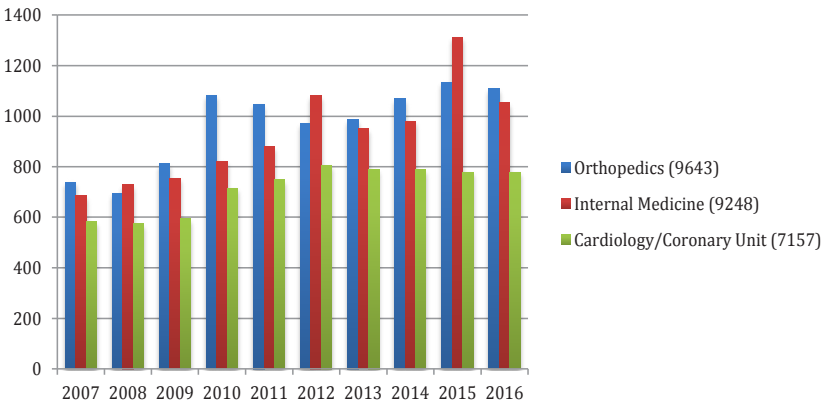

Figure 10: Increase admition to orthopedics, internal medicine and cardiology wards (year/number of patients).

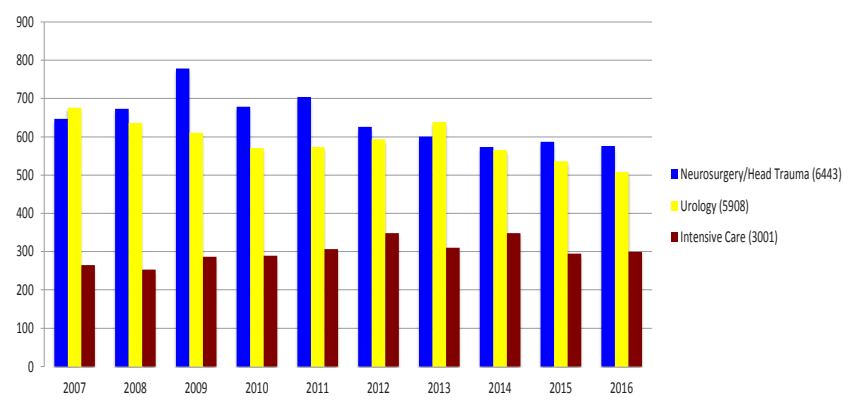

Figure 11: Increase admition to Neurosurgery, Urology and Intensive Care wards (year/number of patients)

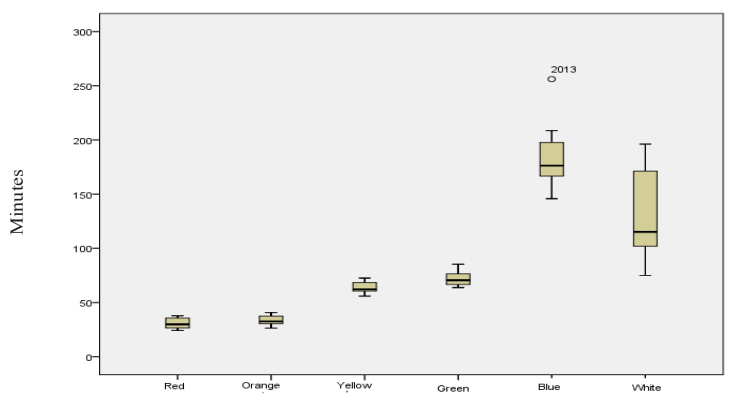

Figure 13: ED episode financing entity.

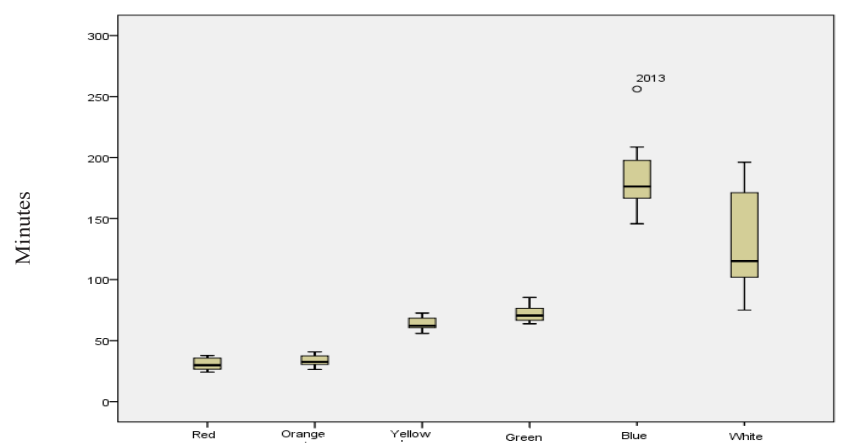

Figure 14: Distribution of the patient average annual waiting time to first medical observation in minutes, considering the Manchester Triage System.

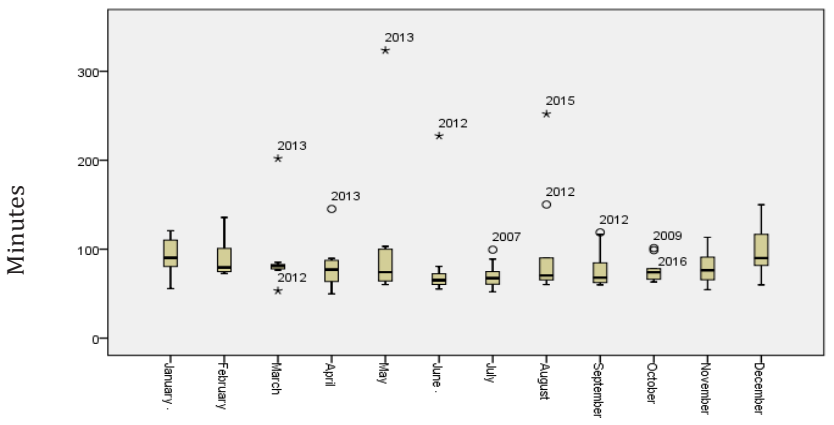

Figure 15: Distribution of the average monthly waiting time to first medical observation in minutes (per year).

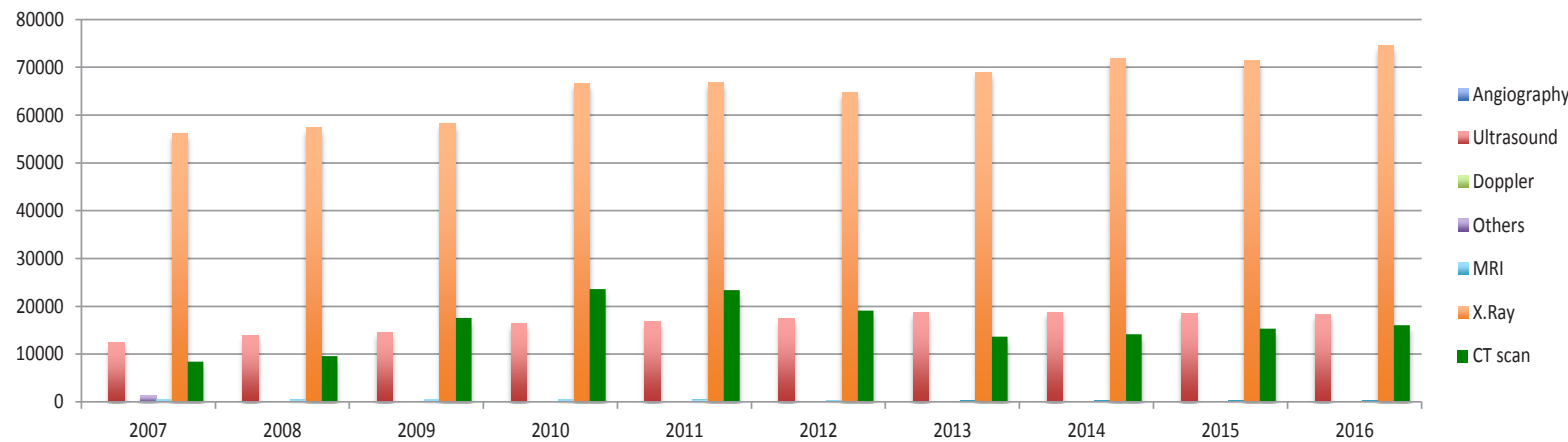

Figure 12: Imaging requests in ED. 


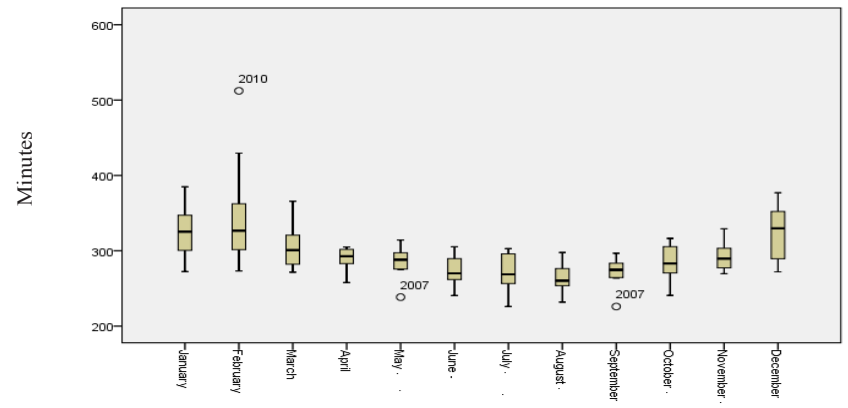

Figure 16: Distribution of the monthly average length of stay in ED in minutes (per year).

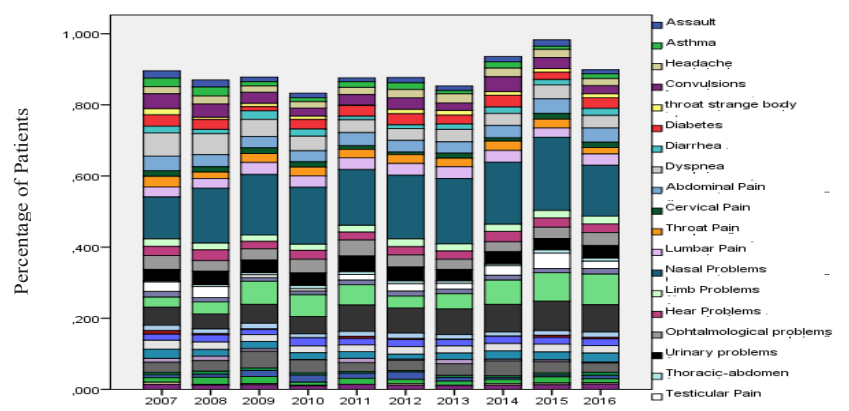

Figure 17: Percentage of readmission to ED with the same complain in the first 72 hours after discharge, per year.

$(\mathrm{p}=0.012)$ decreased throughout the years. Other types of complaint related readmissions have been constant during the study period.

\section{Discussion}

Excluding the private sector, usually not so involved in the emergency department healthcare response when compared to the public hospitals in Portugal, the average number of doctors relative to 1.000 habitants in Portugal is approximately 2.7 (Spain 3.8; France 3.3; United Kingdom 2.8; Holland 3.1; Finland 3.3) [12].

During the period between 2004 to 2014, the population of medical doctors in Portugal increased by a factor of approximately $11 \%$ [12]. In the northern region of Portugal this increase was approximately $9.8 \%$ in 2016 [13], with an increase in family general practitioners (FGP) also reported. With this improvement, only less than a million Portuguese inhabitants are currently without a designated FGP (less than 10\% of the population) [14]. This increase in doctor availability is most relevant in the north of Portugal $[15,16]$, especially in the area covered by the hospital where this study was performed, where the coverage is almost $100 \%$.

The ED human resource team (doctors, nurses, technicians, auxiliaries and administrative clerks) is composed as described in Table 1. ED demand has been stable during the studied period, however an increased about $16 \%$ was observed in the last four years (Table 2). The significant priority 2 (orange) increases and priority 4 (green) decrease accompanied the former facts. These findings might mean that sicker patients still come more often to the ED independently of the increase availability in FGP offer, meaning that people still choose the ED even if they have a designated FGP. On the other hand, it appears that those patients who do not really need to come to the ED (priority 4) still choose to do so but with less frequency, denoting a probable learning effect on this particular ED.

The fact that Priority 4 patients (green) decreased in ED visits might be linked to extensive campaign efforts to inform patients about the ED mission and adequate use; nevertheless, our daily empirical observation is that the Priority 5 patients (blue) do not accept this information and still choose to come to ED.

A decrease in Priority white patients might indicate a good internal (within the hospital) campaign to divert patients away from ED, to be seen elsewhere.

Figure $1 \mathrm{~A}$ shows that during the ten years covered by the study the ED pattern of demand during the day decreased and during the night increased. This might support the idea that this ED is influenced by a local neighborhood effect that could influence demand. Figure 1B shows median numbers of patients arriving in ED at certain hours. The three demand peaks are systematically seen over the years and are mainly between $10 \mathrm{~h}$ and $11 \mathrm{~h}$ in the morning, between $14 \mathrm{~h}$ and 16 $\mathrm{h}$ in the afternoon, and finally a small increase between $21 \mathrm{~h}$ and 22 $\mathrm{h}$ at night, but this last one with a lesser degree of expression when compared to the former two. This pattern coincides with empirical daily practice and is explained by people's daily habits.

Figure $1 \mathrm{~B}$ shows that number of patients that came to the $\mathrm{ED}$ during the more unpopular hours (during the night, from 2 am to 8 am) raised during the study period, indicating that in case of need patients do come to ED. Between $8 \mathrm{~h}$ and $9 \mathrm{~h}$ the $\mathrm{P} 4$ (green) patients almost reach $40 \%$ basically justified by those who do not attend their place of work. Again, in the early morning working hours of the ED ( $8 \mathrm{~h}-9 \mathrm{~h})$ the percentage of the priority white rises, demonstrating that the wrong use of the ED starts early (most of the time, originated by hospital doctors who wrongly schedule appointments with their known patients in the ED).

Following the same pattern of erroneous use of the ED, a slight raise on priority 4 (green) on Sundays shows a consumption pattern of health care services (Figure 2).

The population that comes to the ED in our hospital center, according to age, is shown in Figure 3. It is worth noting that during the studied period the number of patients under 60 years old decreased, with a raise observed after this age bracket. Significantly, it was seen a decrease in the last 5 years of patients between 70 and 80 , with a raise of patients between 80 and 100 years during the same period. These findings support a strong local/regional influence on population demand in the hospital area.

Based on the fact that in Portugal there is no emergency medicine medical specialty, several other specialties work in ED on a rotational basis. Over the last 10 years there was an increase of $79 \%$ of patients seen by General Medicine doctors (Figure 4); of these, some have the General Practitioner specialty and some have no specialty at all. The growing demand for this type of team is related to the increase in the Priority 2 patients (orange) that were redirected Internal Medicine doctors and other specialized clinicians to see these patients, impelling the department to increase not only the number of General Medicine doctors but also increase the percentage of patient cases managed by them. In addition, as expected due to shifts in patient priorities and the potential need for their involvement in the more cases, the number of patients seen by Internal Medicine, and Neurology rose respectively also due to patient aging. Decreases in some specialties (neurosurgery, ophthalmology, nephrology and endocrinology) may be explained by a higher involvement of more embracing specialties with more cases. 
True population aging seen in this ED might be related to this need of a more comprehensive clinical management.

The most common clinical problems that brought patients to the ED are shown in Figure 5 and it's worth noting that pain with three origins (thoracic, abdominal and lumbar) is among the top 7 problems. The unwell patient is the second most common problem, and the limb problems are the most frequent reason that impelled patients to the ED. Dyspnea is included in the top 7 situations, which comprises approximately $62 \%$ of initial ED complaints presented at triage. These facts may induce an evidence-based decision on which specialties and or medical resources should be allocated to the ED. Orthopedics, cardiology, general surgery, ophthalmology, and perhaps general medicine or internal medicine might be included in the most necessary medical resources to be available. Those countries that have a dedicated ED specialty (Accident \& Emergency in the UK or Emergency Medicine in the USA or Canada) may have these specialties in a back office based support to the ED (front office), fact which would impel an especially efficient policy of inpatient-ward turnaround time, due to a more permanent residency of doctors in hospital wards.

For a further rigorous approach to clinical management of the ED, the seasonality of problems should also be addressed; this is shown on Figure 6, and it is very interesting to confirm that in December, January and February, the unwell patient complaint is the most frequent complaint that brings patients to ED. Being dyspnea frequently present during these months, it occurs as the fourth complain, which supports the practice understanding that people during the winter usually complain of being unwell and/or having dyspnea within a set of clinical symptoms, which is confirmed by its raise as a more frequent complaint during this period of the year.

It is noteworthy that $52 \%$ of patients that come to the ED include only five triage clinical problems, namely: limb problems, unwelladult, ophthalmology problems, abdominal pain and dyspnea (Table 3 ). In addition, to reach the $76 \%$ mark of all ED patients within the ten-year period of this study, one had only to include another seven clinical complains, namely: lumbar pain, thoracic pain, ear problems, wounds, urinary problems, headache and local infections (Table 3). This information is of paramount value for organizational purposes and doctor allocation decisions to adjust patient clinical demand to doctor differentiation and expertise. Observing the significance of several incidences in these most frequent complains that brought patients to the ED, management teams may justify why some doctors are more needed during winter and others during summer. Pragmatically, a multispecialty ED team should have a variable management according

\begin{tabular}{|c|c|c|c|}
\hline Clinical Problem & Total of patients & Cumulative & $\%$ of total (cumulative) \\
\hline Limb problem & 195534 & 195534 & $15,56 \%$ \\
\hline Unwell adult & 168055 & 363589 & $28,93 \%$ \\
\hline $\begin{array}{c}\text { Ophthalmological } \\
\text { problems }\end{array}$ & 134231 & 497820 & $39,61 \%$ \\
\hline Abdominal pain & 83195 & 581015 & $46,23 \%$ \\
\hline Dyspnea & 73396 & 654411 & $52,07 \%$ \\
\hline Lumbar pain & 63054 & 717465 & $57,08 \%$ \\
\hline Thoracic pain & 54005 & 771470 & $61,38 \%$ \\
\hline Ear problems & 42976 & 814446 & $64,80 \%$ \\
\hline Wounds & 41056 & 855502 & $68,06 \%$ \\
\hline Urinary problems & 37425 & 892927 & $71,04 \%$ \\
\hline Headache & 36674 & 929601 & $73,96 \%$ \\
\hline Local infections & 30025 & 959626 & $76,35 \%$ \\
\hline
\end{tabular}

Table 3: The most frequent clinical complains presented by ED patients (20072016). to the season in which one refers to. This study evidenced that a winter medical team should expect significant higher numbers of patients with dyspnea, thoracic pain and unspecific complains (like unwell adult), whereas a summer medical team must be prepared to higher number of patients with limb problems, abdominal and lumbar pain, ear and urinary problems and wounds.

The more frequent discharge diagnosis encountered in this study were those belonging to the nervous system/sensory organs (eye, ear), trauma, respiratory, bone/articular, digestive, urinary/genital and circulatory (Figure 7); other diagnostic groups are present, but in a fairly low percentage as compared with the former. The significant increase of respiratory, cardiac/circulatory conditions is consistent with the aging population. Hospital management opened new high dependency units in order to face the increases of these pathologies. Moreover, these findings help to plane future allotment of medical providers in order to match clinical needs. The global diagnostics registration raise, which appears after 2010, is probably linked to an improvement on registration since it happened in all categories and reflects internal department policies to meliorate clinical records.

In Portugal there are very few situations that provide for hospital financial incentives for excellence practice in the public sector. The patient that leaves the ED without being seen (LWBS) or after being seen (LABS), but before formal discharge (for example, while waiting for some clinical decision or analytic result), signifies that these patients are not satisfied. Nevertheless, the ED does not receive incentives if the percentages of LWBS or LABS are kept low. In the studied ED the average percentages are both are below $3 \%$, which is a very good number that indicates a fairly good satisfaction with the service (Figure 8). During these ten years is can be observed that the discharged home and the referencing to the outpatient clinic decreased, showing the clinical impossibility to discharge patients due to their sicker state. Furthermore, according to the formerly stated the admission to ward percentage increased (Figure 8).

A frequently recognized bottleneck in relation to patient admission to a specialty ward is the availability of vacancies. Figure 9 shows the significant increase in intermediate care admition numbers over the studied period. Orthopedics, Internal Medicine, Cardiology and Neurosurgery wards were also the most busy inpatient departments (Figures 10). It is noteworthy to mention the consistent raise in ED intermediate care unit, Orthopedic, Internal Medicine and Cardiology admissions over the last 5 years; this fact might explain why the aging population increases the healthcare workload and demand, since these are specialties/wards that frequently deal with older people. Furthermore, it can be observed that the increase in the admission rate was more than fifty percent in Orthopedics and Internal Medicine. ED intermediate care unit increase of admissions over the studied period (approximately 40\%), is explained by the relatively short number of available vacancies in internal medicine wards.

Figure 11 shows the demand for medical imaging in ED, with an increase in ultrasound, X-ray, and magnetic resonance. This facts may be explained either by a growing in a defensive way of working and either by a growing in junior doctors working in the ED.

Figure 12 shows who has been supporting the costs relative to the ED episodes of the 1256900 patients in our study. The identifiable payers decreased and the unidentified payers increased. This is due to the possibility that, in Portugal, someone who wants to come to the $\mathrm{ED}$ and does not have the means to pay is not stopped from being observed by a doctor. Nevertheless, the payment of a moderation of 
use fee (MF), that is compulsory for the Portuguese public ED user, is implemented, but the common citizen has the possibility to say that he or she has no money at the time, again not being stopped from being seen by a doctor. Since a possible misidentification might be assumed if the patient states that he or she does not "remember" which system covers their health plan, and might not have money with them to pay the MF, this copayment funding might be lost, thus "saving" the patient some money.

Time to first medical observation in the ED is of great importance for patient satisfaction. Figure 13 shows the evolution indexed by triage priority over the study time period. It should be noted that inevitably Priority 1 and 2 have some false observation times due to the severity of the patient condition. No one is worried with electronic medical records if a patient is in a critical condition; the patient is consistently seen and promptly treated in these priorities; only after clinical stabilization are the electronic medical records filled out, with the implication of a bias relating to first observation times for Priority 1 and 2 cases (red and orange). Thus, these priorities did not differ significantly regarding the record time for first medical observation, and a significant decrease was observed, possibly due to a consistent sensitization of medical teams to fulfill the medical records as soon as possible.

In patients with Priority 3 (yellow) and 4 (green), time to first medical observation has been stable over the years at around sixty and under one hundred and twenty minutes respectively, as advocated by the Manchester triage system. Even patients with Priority 5 (blue) have been under the two hundred and forty minutes threshold to first medical observation over the study period. As an assuring observation, patients classified as white (who came erroneously to the ED, sometimes impelled or advised by ED doctors to do so) have been seen after the four first priorities, which might be an overall sign of clinical common sense.

Almost intuitively it could be argued that overall time to first medical observation or contact varies considerably throughout the year. Figure 14 shows that in general, including all patients' priorities over the last ten years, only January and December of some years were well above one hour and ten minutes. The majority of months throughout the years had values under this reference value. However, there are several peaks between October and December 2009, possibly explained by the great affluence to ED due to the breakout of the avian flu. Overall, the worst months throughout the years were invariably December and January, where longer times for first medical observation were found. The avian flu in 2009 caused a sustainable growth in time to first medical observation, which started to increase in September and peaked in December to an astonishing high average of more than two hours and ten minutes.

ED length-of-stay or emergency department episode duration is presented in Figure 15. The general average value throughout the years was found to be under five and half-hours. The best performance (shorter length-of-stay) appeared between June and September, and the longer between December and February. The most significant increases of LOS occurred in February March and October, these due the winter effect and the transition to spring, which imbalances the supply and the demand of ED services. The august peak of LOS might be explained by complexity of trauma cases, since this type of patients empirically increase during summer.

Returning to the ED within seventy-two hours after discharge might imply, amongst other reasons, incomplete clinical improvement and the demand for further medical reassurance. The correlation of readmissions to ED with clinical complaints is of great value for the clinical management of the department. Figure 16 shows the percentage of patients that are readmitted to ED within seventy-two hours, as indexed by complaint over the period of this study. Potential problematic clinical conditions like thoracic pain, abdominal pain, head trauma, and diabetes appear stable over the years. This fact might somehow be a reassuring sign that indicates a consistent strategy of medical management and clinical decision-making, which has been stable over the years. Monitoring readmissions demonstrates an institutional trend in relation to certain types of clinical conditions. Nevertheless, some unexpected facts were observed. Nasal problems, skin eruptions, teeth problems or the apparently drunk person appeared with higher percentages of readmissions; in addition, these higher percentages seem to have empirically increased over the last years, namely on nasal and skin situations and the apparently drunk person (no statistical significance). These three conditions are frequently gathered under the common observation of ED readmission, probably confirming that ED is being misused by patients; either with problems that could be dealt elsewhere (family general practitioner), or with situations that should not be admitted, for example the apparently drunk cases.

Another key feature of this readmission data is the observation of some decrease in several clinical complains along the years. Dyspnea is of relevant importance; in where readmission reduction is clear. One could question about what happened that might justify this finding. In fact, ED implemented an intermediate care unit in 2010, where many of these patients were admitted. This situation not only improved the treatment but also decreased the need to return to ED.

The results encountered in this study due to patient volume, despite being a retrospective study, may indicate a fair amount of relevant trends that are worth noting for medical management and decisionmaking.

Limitations of this study are linked to its retrospective nature, with the possibility of occurrence of data blanks due to the large amount of patients included.

The authors found the need for further studies, namely of prospective nature, randomized and controlled in order to clarify some of the problems encountered during this data analysis.

\section{Key Learning Points}

1. A total number of $1,256,900$ patients were studied in this ten years' series of cases, showing the global utilization trends of this Emergency Department at Centro Hospitalar do Porto, Portugal.

2. The geographical area covered by this study's ED has a negligible percentage of users without an assigned Family General Practitioner (FGP) $[12,13]$.

3. This ED demand increased by $16 \%$ in the last four years.

4. Sicker patients increased in ED, even with an assigned Family General Practioner, meaning that users chose to attend the ED even with primary care coverage.

5. Three demand peaks were observed over the years, namely between $10 \mathrm{~h}$ and $11 \mathrm{~h}, 14 \mathrm{~h}$ and $16 \mathrm{~h}$, and a smaller one between $21 \mathrm{~h}$ and $22 \mathrm{~h}$. Likewise, unpopular hours (during late night) were when the sicker patients (the ones who really need care - higher priorities) come in a higher percentage. 
6. The aging population is confirmed in this study with a decrease in all age intervals till 60 years old. A rise in the number of patients between 80 and 100 years old was observed.

7. In the last 10 years there was an increase of $79 \%$ of patients seen by the General Medicine doctors in this ED, with a busier Internal Medicine area due to the aging population with more complex cases.

8. Limb and eye problems, thoracic, abdominal and lumbar pain, along with the categorized "unwell adult" and dyspnea were the seven most common reasons that brought patients to ED, comprising more than two thirds of the initial clinical complaints.

9. Winter months had significantly more patients with dyspnea and thoracic pain, whereas summer months had a predominance of lumbar and abdominal pain, wounds, limb ear and urinary problems. Thus, it might me reasonable to have a season adjusted medical team.

10.Average number of patients that left-without-being-seen (LWBS) was consistently under $2.5 \%$, a considered international good patient satisfaction indicator.

11.A consistent, over the years, increase in hospitalization rates to the wards, was seen for specialties that deal with older patients (ED intermediate care unit, Internal Medicine, Orthopedics, Cardiology and Neurology).

12.Despite certain enlarged waiting-to-be-seen (WTBS) periods, priority 3 patients (yellow) have been observed by a doctor within the proposed time by the Manchester Triage System.

13. Only on January and December of some years in the studied period, had the average median time to first medical observation been above one hour

14.The ED overall average length-of-stay (LOS) value was found to be under five and half-hours.

15.Readmissions until 72 hours after discharge from ED of more serious clinical conditions like thoracic pain, abdominal pain, head trauma, and diabetes mellitus were stable and clinically acceptable over the years.

16. Non-complex cases that return before 72 hours after discharge, confirm that ED was misused, with problems that could be dealt by the family general practitioner.

17. Hospital intermediate care unit implementation was linked to a decrease of readmissions by dyspnea/respiratory problems.

18.ED clinical data were consistently stored, meaning that it can be accountable and trustworthy for this or other studies.

19.Primary care offer did not seem to influence ED demand, and population changes and preferences were reflected in ED operational data.

20.Evidence based clinical management may improve, if systematic clinical data storage becomes continually kept in this or other Emergency Departments.

\section{Conclusion}

ED affluence increased during the studied period, especially by the older and the sicker.

Primary care coverage over the studied area increased availability did not influence ED demand.

Real time data storage helped to maintain clinical management by evidence based decisions.

\section{Declarations}

None of the authors have any conflicts of interest related to this study.

All authors give their consent for the publication of this study.

Data used in this study is digitally stored in a data warehouse and is institutionally available for further studies or confirmation analysis.

All authors participated in the study design.

Data collection was carried out by Humberto S Machado, António Marques, Isabel Almeida and António José Barros. Data assembly was check by all authors. Statistical analysis was performed by CSN and HSM. Writing, editing and revision was carried out by Humberto $S$ Machado, Catarina Nunes, António Marques, Eurico Castro Alves, António Sousa Pereira, José Barros and Paulo Barbosa.

\section{References}

1. Fernandes C (2003) Emergency department overcrowding: What is our response to the "new normal"? Emerg Med 10: 1096-1097.

2. Richardson DB (2006) Increase in patient mortality at 10 days associated with emergency department overcrowding. Med J Aust 184: 213-216.

3. Hwang U, Concato J (2004) Care in the emergency department: How crowded is overcrowded? Emerg Med 11: 1097-1101.

4. Liew D, Kennedy MP (2003) Emergency department length of stay independently predicts excess inpatient length of stay. Med J Aust 179: 524-526.

5. Richardson DB (2002) The access-block effect: Relationship between delay to reaching an inpatient bed and inpatient length of stay. Med J Aust 177: 492-505.

6. Trzeciak S, Rivers EP (2003) Emergency department overcrowding in the United States: An emerging threat to patient safety and public health. J Emerg Med 20: 402-405.

7. Moseley MG, Moore T, Vagarali A, Rund D (2010) Surge: An organizational response to emergency department overcrowding. JCOM 17.

8. Jayaprakash N, O'Sullivan R, Bey T, Ahmed SS, Lotfipour S, et al. (2009) Crowding and delivery of healthcare in emergency departments: The european perspective. West J Emerg Med 10: 233-239.

9. Geelhoed GC, de Klerk NH (2012) Emergency department overcrowding, mortality and the 4-hour rule in Western Australia. J Med Austr 196: 122-126.

10. Boyle A, Beniuk K, Higginson I, Atkinson P (2012) Emergency department crowding: Time for interventions and policy evaluations. Emerg Med Int.

11. Mason S, Mountain G, Turner J, Arain M, Weber EJ, et al. (2014) Innovations to reduce demand and crowding in emergency care; A review study. Scand $\mathrm{J}$ Trauma Resusc Emerg Med 22: 55.

12. Santos MD (2017) Rotativity in a hospital center of group E: Visualization and analysis of information to support management. InAtas of the Conference of the Portuguese Association of Information Systems 17: 1-22.

13. http://www.acss.min-saude.pt/2017/02/20/2016-com-maior-atividadeassistencial-e-com-mais-portugueses-com-medico-de-familia/

14. http://www.acss.min-saude.pt/2016/12/02/colocados-mais-73-medicos-defamilia/

15. Hsia RY, Asch SM, Weiss RE, Zingmond D, Liang LJ, et al. (2011) Hospital determinants of emergency department left without being seen rates. Ann Emerg Med 58: 1. 